\title{
Regulation of the antiapoptotic protein cFLIP by the glucocorticoid Dexamethasone in ALL cells
}

\author{
Lara Kleinesudeik ${ }^{1,2,3}$, Katharina Rohde ${ }^{1}$ and Simone Fulda ${ }^{1,2,3}$ \\ ${ }^{1}$ Institute for Experimental Cancer Research in Pediatrics, Goethe-University, Frankfurt, Germany \\ ${ }^{2}$ German Cancer Consortium (DKTK), Partner site Frankfurt, Germany \\ ${ }^{3}$ German Cancer Research Center (DKFZ), Heidelberg, Germany \\ Correspondence to: Simone Fulda, email: simone.fulda@kgu.de
}

Keywords: apoptosis; CFLIP; glucocorticoid; Smac mimetic

Received: December 13, $2017 \quad$ Accepted: February 26, $2018 \quad$ Published: March 27, 2018

Copyright: Kleinesudeik et al. This is an open-access article distributed under the terms of the Creative Commons Attribution License 3.0 (CC BY 3.0), which permits unrestricted use, distribution, and reproduction in any medium, provided the original author and source are credited.

\section{ABSTRACT}

We recently reported that the Smac mimetic BV6 and glucocorticoids, e.g. Dexamethasone (Dexa), synergize to induce cell death in acute lymphoblastic leukemia (ALL) in vitro and in vivo. Here, we discover that this synergism involves Dexa-stimulated downregulation of cellular FLICE-like inhibitory protein (cFLIP) in ALL cells. Dexa rapidly decreases CFLIP $_{L}$ protein levels, which is further enhanced by addition of BV6. While attenuating the activation of non-canonical nuclear factorkappaB (NF-kB) signaling by BV6, Dexa suppresses cFLIP $P_{L}$ protein but not mRNA levels pointing to a transcription-independent downregulation of $C_{F L I P}$ by Dexa. Analysis of protein degradation pathways indicates that Dexa causes cFLIP $P_{L}$ depletion independently of proteasomal, lysosomal or caspase pathways, as inhibitors of the proteasome, lysosomal enzymes or caspases all failed to protect from Dexa-mediated loss of CFLIP ${ }_{L}$ protein. Also, Dexa alone or in combination with BV6 does not affect overall activity of the proteasome. Importantly, overexpression of CFLIP $_{L}$ to an extent that is no longer subject to Dexa-imposed downregulation rescues Dexa/ BV6-mediated cell death. Vice versa, knockdown of cFLIP increases BV6-mediated cell death, thus mimicking the effect of Dexa. Altogether, these data demonstrate that Dexa-mediated downregulation of $\mathrm{CFLIP}_{\mathrm{L}}$ protein promotes Dexa/BV6-mediated cell death, thereby providing novel insights into the synergistic antitumor activity of this combination treatment.

\section{INTRODUCTION}

Apoptosis is one of the best characterized forms of programmed cell death and a crucial process in physiological and pathophysiological conditions [1]. Its execution is tightly regulated by several proteins, like Inhibitor of Apoptosis (IAP) proteins [2] or cFLIP [3]. Evasion of programmed cell death is a hallmark of cancer and accomplished, for example, by aberrant expression of antiapoptotic proteins.

One major cell death regulator is cFLIP. High cFLIP expression is correlated with a poor prognosis in several tumor entities [4-6] and its downregulation is part of effective drug-mediated cell death [7]. There are two main isoforms of cFLIP expressed in human cells which control cell death in a distinct manner: The long isoform $\mathrm{cFLIP}_{\mathrm{L}}$, a $55 \mathrm{kDa}$ protein, and the short isoform $\mathrm{cFLIP}_{\mathrm{s}}$, a $25 \mathrm{kDa}$ protein [3]. cFLIP is a caspase-8/-10 homolog with two death effector domains (DEDs), but with an inactive caspase domain. Its influence on cell death regulation is being controversially discussed, as it is reported to exert pro- or antiapoptotic effects, depending on the context. Lower levels of cFLIP ${ }_{L}$ are associated with a proapoptotic function, as highly active heterodimers are formed [8]. In higher concentrations, $\mathrm{cFLIP}_{\mathrm{L}}$ prevents caspase- 8 activation in the death-inducing signaling complex (DISC) 
[9], which is formed upon death receptor-mediated cell death and caspase- 8 activation in the ripoptosome, a signaling platform formed upon IAP depletion $[10,11]$. $\mathrm{cFLIP}_{\mathrm{S}}$ consists only of two DEDs and directly inhibits caspase- 8 activation at the DISC [9] and the ripoptosome $[10,11]$ and thereby apoptosis.

Other cell death-regulating proteins are IAP proteins which are known to be prognostic factors in different tumor entities [12]. Their inhibition as therapeutic approach has been intensively studied and IAP antagonists including Smac mimetics have been developed. Smac mimetics, e.g. BV6, induce autoubiquitination and proteasomal degradation of IAP proteins and have been shown to promote cell death induced by different stimuli [13].

New treatment strategies are required for ALL, as the prognosis for relapsed patients is still poor [14]. We previously discovered that the Smac mimetic BV6 sensitizes ALL cells to glucocorticoids, such as Dexa, which are part of the standard therapy of ALL patients, by promoting the formation of the ripoptosome complex and by exerting antileukemic activity in a patient-derived xenograft model of ALL in vivo [15]. The assembly of the ripoptosome is regulated, amongst others, by the two major isoforms of cFLIP, i.e. cFLIP ${ }_{L}$ and cFLIP $_{S}[10,11]$. Therefore, we studied the role of cFLIP in regulating Dexa/BV6-mediated cell death to gain new insights into the molecular mechanisms underlying the synergism of Dexa and BV6.

\section{RESULTS}

\section{Dexa downregulates cFLIP ${ }_{L}$ protein in ALL cells}

Initially, we determined protein expression of the two major isoforms of cFLIP (i.e. cFLIP $_{L}$ and $\mathrm{cFLIP}_{\mathrm{S}}$ ) in ALL cell lines. Since all analyzed ALL cell lines predominately expressed $\mathrm{CFLIP}_{\mathrm{L}}$ rather than $\mathrm{CFLIP}_{\mathrm{S}}$ protein (Supplementary Figure 1), we focused our analysis in ALL on $\mathrm{CFLIP}_{\mathrm{L}}$. We then asked whether Dexa as single agent or in combination with BV6 affects cFLIP ${ }_{L}$ levels. Interestingly, treatment with Dexa alone or together with BV6 downregulated $\mathrm{cFLIP}_{\mathrm{L}}$ protein levels already after a few hours (Figure 1A). To examine whether the loss of $\mathrm{cFLIP}_{\mathrm{L}}$ protein is due to changes in mRNA expression, we performed qRT-PCR analysis. Dexa treatment increased rather than suppressed $\mathrm{cFLIP}_{\mathrm{L}}$ mRNA levels (Figure 1B), indicating that the observed loss of $\mathrm{CFLIP}_{\mathrm{L}}$ protein by Dexa or Dexa/BV6 treatment is independent of mRNA expression. These data indicate a Dexa-mediated downregulation of $\mathrm{CFLIP}_{\mathrm{L}}$ protein independent of mRNA expression.

\section{Dexa impedes BV6-stimulated NF-kB activation}

Since Smac mimetics have been described to deplete IAP proteins [16, 17], we determined expression levels of cellular IAP (cIAP)1, cIAP2 and x-linked IAP
(XIAP) upon treatment with Dexa and BV6. As expected, treatment with either BV6 alone or in combination with Dexa caused a loss of cIAP1 and cIAP2 in all four cell lines and XIAP expression slightly decreased by Dexa/ BV6 cotreatment (Figure 2A). In KOPN-8;11 cells, we did not detect cIAP2 protein (Figure 2A).

As loss of cIAP proteins can lead to activation of the non-canonical NF- $\kappa B$ pathway $[16,17]$, we next assessed expression of NF- $\kappa \mathrm{B}$-inducing kinase (NIK) and p100/ p52 as key components of non-canonical NF- $\kappa B$ signaling. Treatment with BV6 caused accumulation of NIK protein (Figure 2B), in line with the observed BV6-imposed depletion of cIAP proteins (Figure 2A), which serve as E3 ligases of NIK [16]. In addition, BV6 increased NIK mRNA expression (Figure 2C). Interestingly, addition of Dexa abolished the BV6-mediated accumulation of NIK protein (Jurkat, KOPN-8;11, Reh) or reduced it (Molt-4) (Figure 2B). Consistently, addition of Dexa slightly diminished the BV6-mediated processing of the NF- $\kappa \mathrm{B}$ precursor p100 to p52 in all four cell lines (Figure 2B). Altogether these data indicate that Dexa impedes the BV6triggered activation of $\mathrm{NF}-\kappa \mathrm{B}$.

\section{Dexa-stimulated downregulation of CFLIP $_{L}$ protein occurs largely independent of the proteasome, lysosomal enzymes and caspases}

Since our data point to a transcription-independent regulation of $\mathrm{cFLIP}_{L}$, we investigated whether Dexastimulated downregulation of $\mathrm{cFLIP}_{\mathrm{L}}$ is due to changes in cellular protein degradation pathways. CFLIP $_{\mathrm{L}}$ is described as short-lived protein, which is primarily regulated by the ubiquitin-proteasomal pathway [18]. To determine the half-life of $\mathrm{cFLIP}_{\mathrm{L}}$ in ALL cell lines, we performed cycloheximide (CHX) chase assays to assess cFLIP ${ }_{\mathrm{L}}$ levels upon inhibition of protein synthesis by $\mathrm{CHX}$. CHX treatment caused a rapid decrease in $\mathrm{CFLIP}_{\mathrm{L}}$ protein (Figure $3 \mathrm{~A}$ ). To analyze the role of the proteasomal pathway, we blocked the proteasome by the specific inhibitor Bortezomib. The addition of Bortezomib delayed loss of $\mathrm{CFLIP}_{\mathrm{L}}$ protein upon protein synthesis inhibition, in particular in Reh cells, but did not completely rescue it, whereas loss of Noxa protein, a known target of the proteasome, was partially restored in both cell lines (Figure 3A), indicating that $\mathrm{cFLIP}_{\mathrm{L}}$ is not strictly regulated by the proteasome in the analyzed cell lines. To explore whether loss of $\mathrm{cFLIP}_{\mathrm{L}}$ protein upon Dexa treatment is mediated via the proteasome, we added Bortezomib to Dexa-treated cells. Interestingly, Bortezomib failed to rescue Dexa-mediated loss of $\mathrm{CFLIP}_{\mathrm{L}}$ protein (Figure 3B). To assess whether Dexa directly impairs proteasome activity, we performed a proteasome activity assay. Dexa alone or in combination with BV6 did not alter 20S proteasome activity (Figure 3C). By comparison, Dexa treatment had little effects on other short-lived proteins at early time points, such as Noxa or Mcl-1 (Supplementary Figure 2). 
A

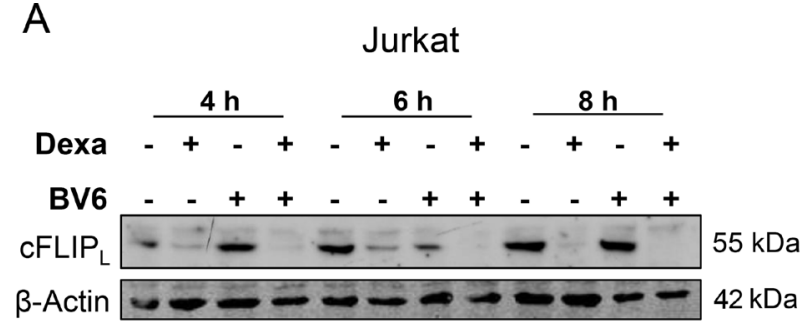

KOPN-8;11

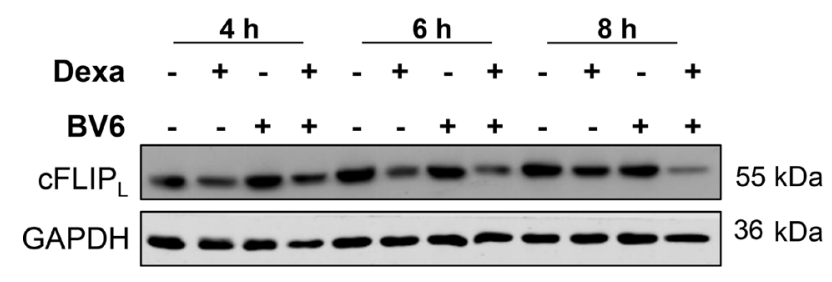

Molt-4
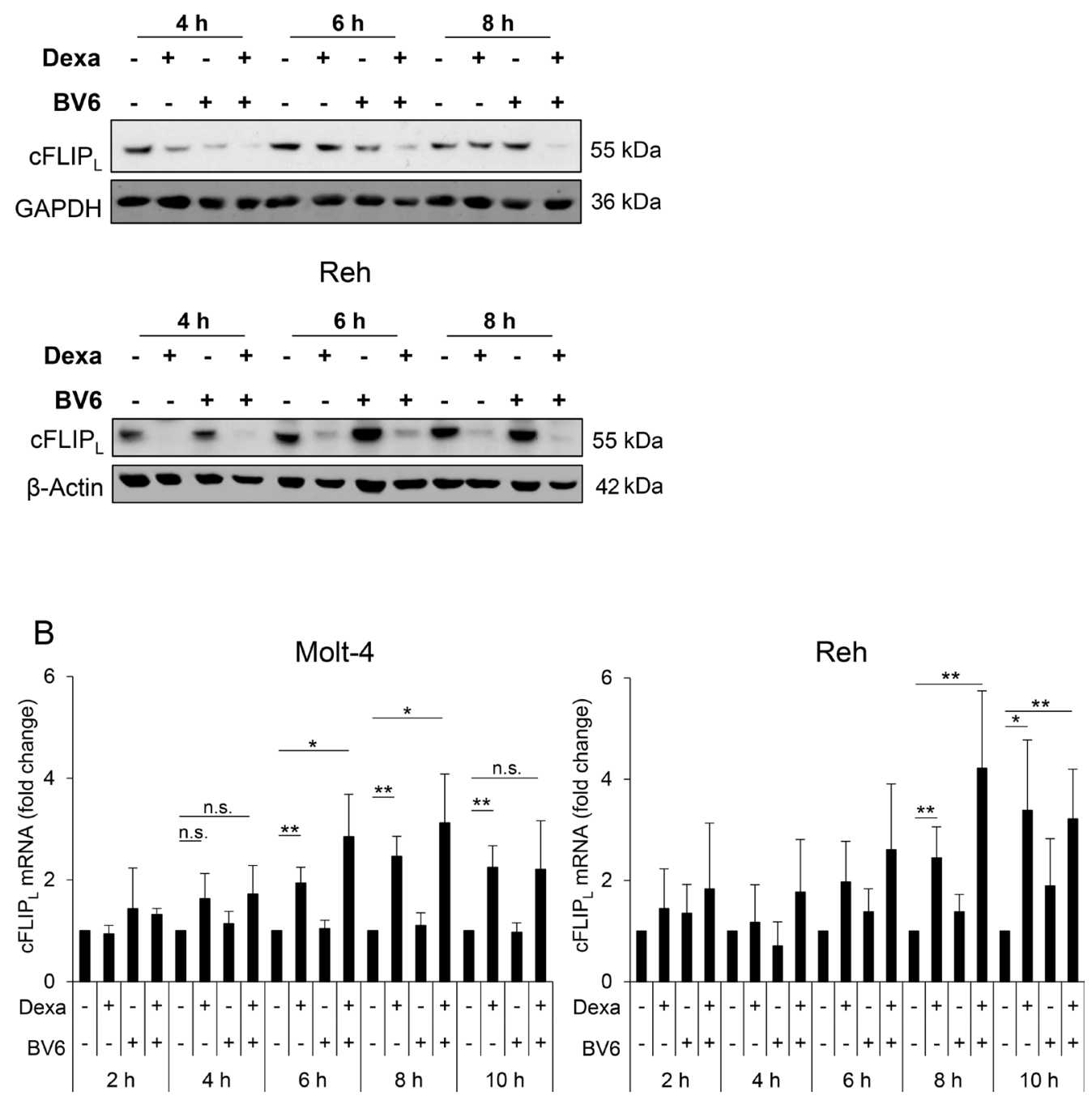

Figure 1: Dexa downregulates CFLIP $_{L}$ protein in ALL cells. ALL cells were treated for indicated time points with Dexa and/or BV6 (Jurkat: $300 \mu$ M Dexa, $7 \mu$ M BV6; KOPN-8;11: $150 \mu$ M Dexa, $2 \mu$ M BV6; Molt-4: $300 \mu$ M Dexa, $5 \mu$ M BV6; Reh: $300 \mu$ M Dexa, $0.3 \mu \mathrm{M}$ BV6). (A) Protein expression of $\mathrm{cFLIP}_{\mathrm{L}}$ was analyzed by Western blotting. $\beta$-Actin or GAPDH served as loading control. (B) $\mathrm{cFLIP}_{\mathrm{L}} \mathrm{mRNA}$ levels were analyzed using qRT-PCR. Fold change of $\mathrm{cFLIP}_{\mathrm{L}} \mathrm{mRNA}$ as mean and standard deviation (SD) of at least three independent experiments are shown. 

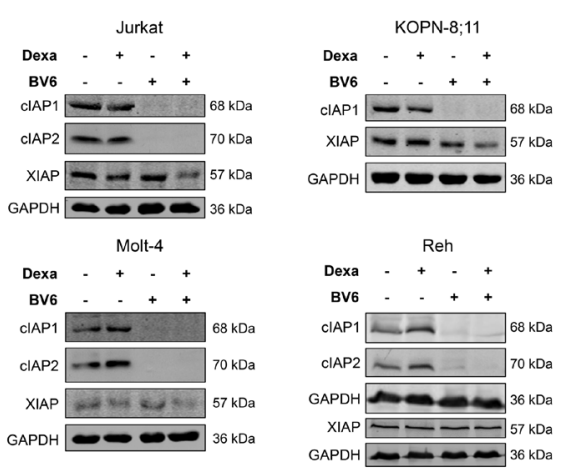

B

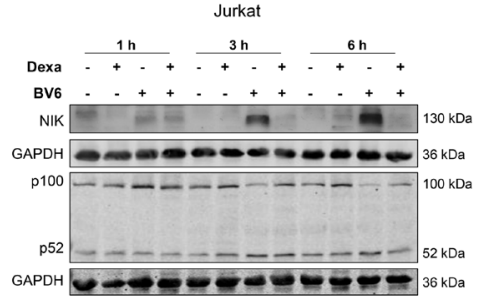

KOPN-8;11

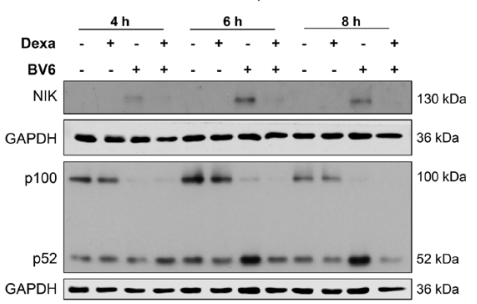

Molt-4
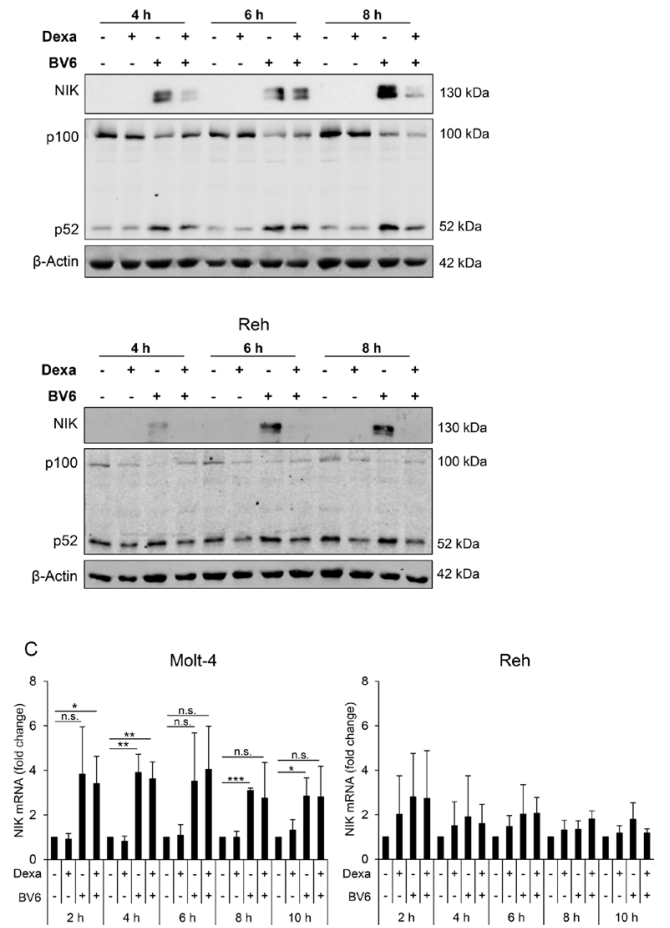

Figure 2: Dexa impedes BV6-stimulated NF-KB activation. ALL cells were treated for four hours (A) or indicated time points (B, C) with Dexa and/or BV6 (Jurkat: $300 \mu$ M Dexa, $7 \mu$ M BV6; KOPN-8;11: $150 \mu$ M Dexa, $2 \mu$ M BV6; Molt-4: $300 \mu$ M Dexa, $5 \mu \mathrm{M}$ BV6; Reh: $300 \mu \mathrm{M}$ Dexa, $0.3 \mu \mathrm{M}$ BV6). (A) Protein expression of cIAP1, cIAP2 and XIAP was analyzed by Western blotting. GAPDH served as loading control. (B) Protein expression of NIK and p100/p52 was analyzed by Western blotting. $\beta$-Actin or GAPDH served as loading control. (C) NIK mRNA levels were analyzed using qRT-PCR. Fold change of NIK mRNA as mean and SD values of at least three independent experiments are shown. 
To investigate whether $\mathrm{cFLIP}_{\mathrm{L}}$ protein is degraded upon Dexa treatment via the lysosomal pathway, we blocked lysosomal enzymes by different pharmacological inhibitors. All of them (alone or in combination) failed to prevent loss of cFLIP $_{L}$ protein after Dexa treatment (Figure 3D). Since cFLIP $_{\mathrm{L}}$ is a known target of caspase-8, we analyzed whether caspase-mediated cleavage of $c$ FLIP ${ }_{L}$ is responsible for its loss upon Dexa treatment. But the addition of N-benzyloxycarbonyl-Val-Ala-Asp-(OMe)fluoromethylketone (zVAD.fmk), a pan-caspase inhibitor, did not prevent Dexa-mediated downregulation of cFLIP (Figure 3E). This set of experiments indicates that Dexamediated loss of $\mathrm{cFLIP}_{\mathrm{L}}$ protein in ALL cell lines is not primarily mediated via the proteasome, lysosomal enzymes or caspases.

\section{High cFLIP ${ }_{L}$ levels impair Dexa/BV6-mediated cell death in Reh cells}

To explore the functional relevance of $\mathrm{CFLIP}_{\mathrm{L}}$ in Dexa/BV6-mediated cell death, we created cell lines stably overexpressing $\mathrm{cFLIP}_{\mathrm{L}}$ (Figure 4A, 4C, 4E). Of note, cFLIP $_{L}$ overexpression significantly reduced Dexa/BV6- as well as BV6-mediated cell death in Reh cells (Figure 4B), in which the ectopically expressed cFLIP $_{\mathrm{L}}$ protein was resistant to Dexa/BV6-imposed downregulation (Figure 4G). In Jurkat and Molt-4 cells, Dexa/BV6 downregulated ectopically expressed $\mathrm{cFLIP}_{\mathrm{L}}$ in addition to endogenous cFLIP $_{L}$ protein (Figure 4G), consistent with the failure of $\mathrm{CFLIP}_{\mathrm{L}}$ overexpression to rescue Dexa/BV6-induced cell death in these cell lines (Figure 4D, 4F). Control experiments confirmed that $\mathrm{cFLIP}_{\mathrm{L}}$ overexpression significantly reduced $\mathrm{TNF} \alpha /$ BV6-mediated cell death in Jurkat and Molt-4 cells (Supplementary Figure 3). In line with the $\mathrm{cFLIP}_{\mathrm{L}^{-}}$ conferred protection from Dexa/BV6-induced cell death

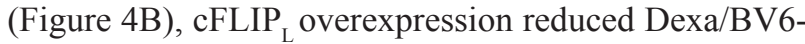
imposed cleavage of caspase- 8 , caspase- 9 and caspase- 3 compared to Reh control cells expressing empty vector (EV) (Figure 4H), whereas overexpression of cFLIP ${ }_{L}$ had little effects on Dexa/BV6-induced caspase cleavage in Jurkat cells (Figure 4H). These data show that high cFLIP ${ }_{L}$ levels impair Dexa/BV6-mediated cell death in a cell linedependent manner.

\section{Knockdown of cFLIP increases BV6-mediated cell death}

Next, we tested the functional relevance of Dexamediated loss of cFLIP protein to sensitize ALL cells to BV6 by siRNA-mediated knockdown of cFLIP to mimic its depletion by Dexa. In all tested cell lines, knockdown of cFLIP by using two independent siRNA sequences (Figure 5A, 5C, 5E, 5G) caused an increase in TNFa/ BV6-mediated cell death that served as positive control (Figure 5B, 5D, 5F, 5H). Importantly, cFLIP knockdown significantly increased BV6-mediated cell death in KOPN$8 ; 11$ cells (Figure 5D). In Jurkat and Reh cells, cFLIP knockdown by using sequence \#1 significantly enhanced cell death in BV6-treated cells (Figure 5B, 5G), while cFLIP silencing did not alter BV6-induced cell death in Molt-4 cells (Figure 5F). These results demonstrate that cFLIP silencing increases BV6-mediated cell death in a cell line-dependent manner.

\section{DISCUSSION}

\section{Regulation of Smac mimetic-induced cell death by cFLIP}

In the present study, we discover that Dexa-imposed suppression of $\mathrm{cFLIP}_{\mathrm{L}}$ contributes to Dexa/BV6-induced cell death. The conclusion that $\mathrm{CFLIP}_{\mathrm{L}}$ negatively regulates Dexa/ BV6-induced cell death is supported by our data showing that overexpression of $\mathrm{cFLIP}_{\mathrm{L}}$ to an extent that is no longer subject to Dexa-mediated downregulation rescues Dexa/ BV6-mediated cell death. In addition, knockdown of cFLIP mimics Dexa treatment in ALL, as it increases BV6-mediated cell death. All these findings underscore the functional relevance of cFLIP in Dexa/BV6-mediated cell death. Since we previously demonstrated that Dexa/BV6-induced depletion of cIAP proteins is followed by ripoptosome formation [15], which is known to be negatively regulated by cFLIP $[10,11,19]$, reduction of cFLIP protein levels by Dexa/ BV6 treatment may well promote ripoptosome formation and thereby cell death. Thus, in addition to downregulating cIAP proteins, Dexa/BV6-induced suppression of cFLIP contributes to Dexa/BV6-mediated cell death.

cFLIP is a well-described negative regulator of cell death in many tumor entities and treatment strategies. cFLIP has been shown to protect from Smac mimeticinduced cell death $[20,21]$ and silencing of cFLIP was found to sensitize different tumor cell lines to Smac mimetics $[21,22]$. Also, there are several reports showing that cFLIP can protect cancer cells from TRAIL-, CD95or chemotherapy-induced cell death [23-26].

\section{Molecular mechanisms of cFLIP downregulation}

Furthermore, our study provides new insights into the molecular mechanisms that are responsible for Dexa-imposed downregulation of cFLIP protein. cFLIP expression is tightly regulated by various transcriptional and post-transcriptional mechanisms. While cFLIP is known to be regulated by different transcription factors including NF- $\mathrm{NB}[27,28]$, our data point to a transcription-independent regulation of cFLIP by Dexa, as Dexa suppressed cFLIP ${ }_{L}$ protein but not mRNA levels. Nevertheless, Dexa attenuated BV6-stimulated noncanonical NF- $\kappa \mathrm{B}$ activation in ALL cell lines, which is consistent with other reports showing that glucocorticoids such as Dexa can block NF-кB [29-31]. 
A

Molt-4

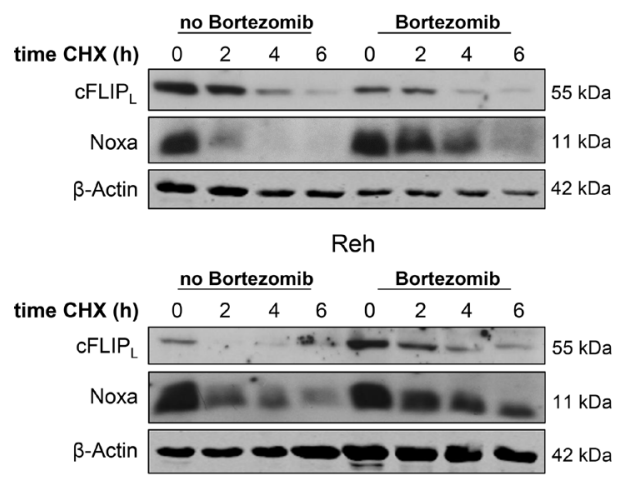

B
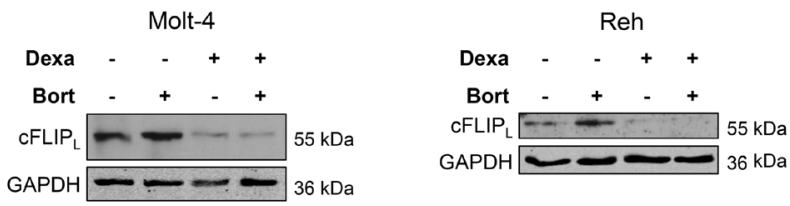

C
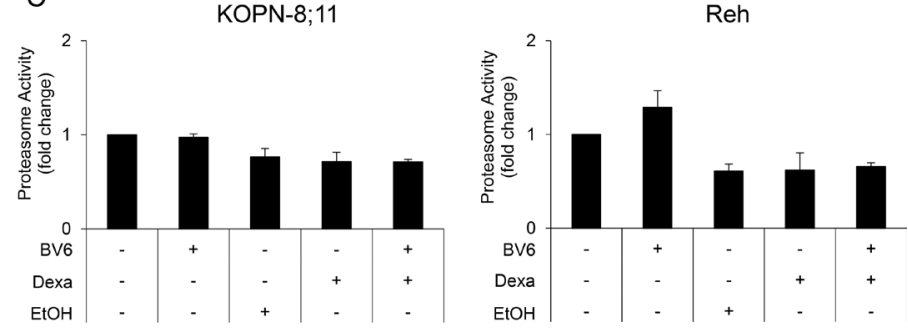

D

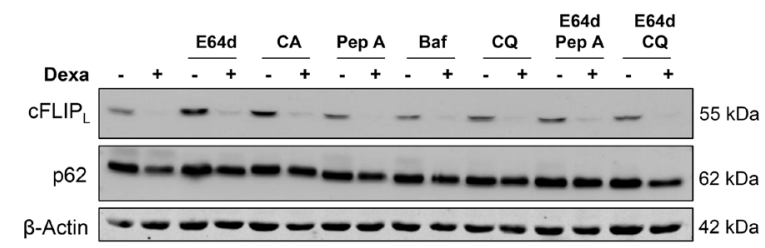

$\mathrm{E}$

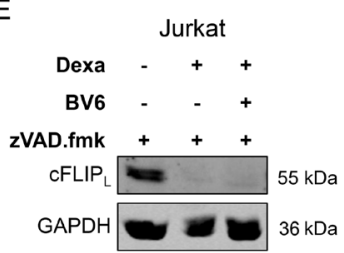

Reh

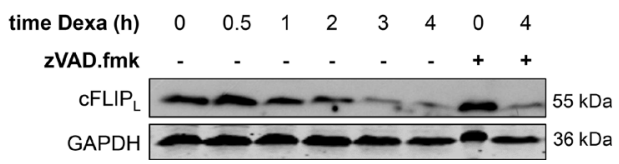

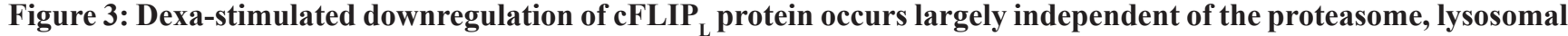
enzymes and caspases. (A) Molt-4 and Reh cells were treated with $30 \mathrm{nM}$ Bortezomib to block proteasomal activity, after one hour cells were treated with $10 \mathrm{ng} / \mathrm{ml} \mathrm{CHX}$ for indicated time points. Expression of $\mathrm{cFLIP}_{\mathrm{L}}$ and Noxa was analyzed by Western blotting. $\beta$-Actin served as loading control. (B) Molt-4 and Reh cells were treated with $30 \mathrm{nM}$ Bortezomib (Bort) to block proteasomal activity, after one hour cells were treated with $300 \mu \mathrm{M}$ Dexa for four hours. Expression of $\mathrm{cFLIP}_{\mathrm{L}}$ was analyzed by Western blotting. GAPDH served as 
loading control. (C) Proteasome activity was analyzed using Chemicon 20S Proteasome Activity Assay. Fold change of proteasome activity of two independent experiments performed in duplicates is shown. EtOH was used as solvent for Dexa. (D) Reh cells were incubated with inhibitors of lysosomal enzymes $(10 \mu \mathrm{g} / \mathrm{ml}$ E64d, $10 \mu \mathrm{g} / \mathrm{ml} \mathrm{CA-074} \mathrm{methyl} \mathrm{ester} \mathrm{(CA),} 10 \mu \mathrm{g} / \mathrm{ml}$ Pepstatin A (Pep A), $50 \mathrm{nM} \mathrm{Bafilomycin}$ $\mathrm{A}$ (Baf), $25 \mu \mathrm{M}$ Chloroquine (CQ)) for one hour, followed by treatment with $300 \mu \mathrm{M}$ Dexa for four hours. cFLIP ${ }_{L}$ protein expression was analyzed using Western blotting. $\beta$-Actin served as loading control. (E) Jurkat and Reh cells were treated with $20 \mu \mathrm{M}$ zVAD.fmk and 300 $\mu \mathrm{M}$ Dexa for four hours or indicated time points. $\mathrm{cFLIP}_{\mathrm{L}}$ expression was analyzed by Western blotting. GAPDH served as loading control.

cFLIP is known as a short-lived protein and its turnover has been shown to determine sensitivity to cell death, e.g. to death receptor signals [32]. Several E3 ubiquitin ligases, for example Itch [33, 34], have been identified that polyubiquitinate cFLIP to induce its proteasome-mediated proteolysis, and proteasome inhibitors have been described to rescue the degradation of cFLIP protein $[35,36]$. In addition, increased proteasome activity is associated with downregulation of cFLIP protein [37]. However, our findings suggest that Dexainduced loss of $\mathrm{cFLIP}_{\mathrm{L}}$ protein is not primarily due to increased proteasomal degradation, since i) addition of the proteasome inhibitor Bortezomib failed to fully protect from Dexa-induced loss of cFLIP protein and since ii) treatment with Dexa alone or in combination with BV6 did not alter $20 \mathrm{~S}$ proteasomal activity.

Besides proteasome-mediated proteolysis, tumor necrosis factor (TNF) receptor-associated factor (TRAF)7, another E3 ubiquitin ligase, has been described to polyubiquitinate cFLIP and to induce its lysosomal degradation [38]. However, our findings suggest a lysosome-independent downregulation of $\mathrm{cFLIP}_{\mathrm{L}}$, as inhibition of several lysosomal enzymes, either alone or in combination, failed to rescue Dexa-stimulated $\mathrm{cFLIP}_{\mathrm{L}}$ degradation. It is also unlikely that caspase-8-triggered cleavage of $\mathrm{cFLIP}_{\mathrm{L}}$ is responsible for its downregulation
A

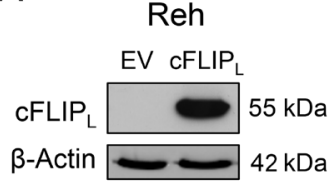

C

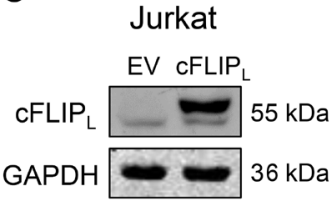

$E$

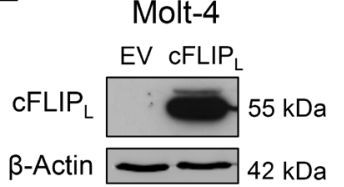

B

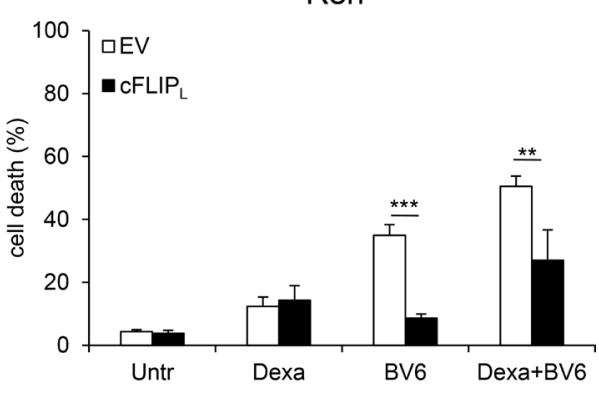

D

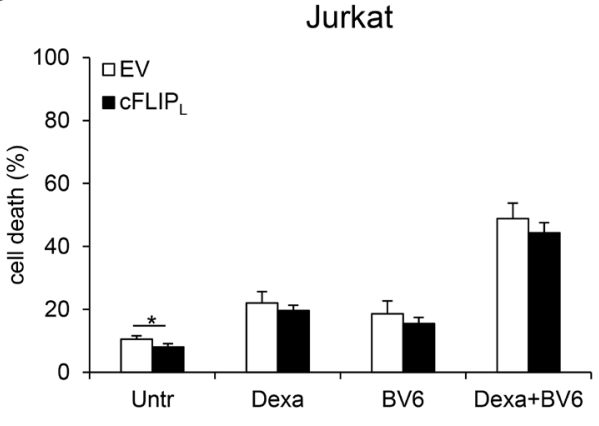

F

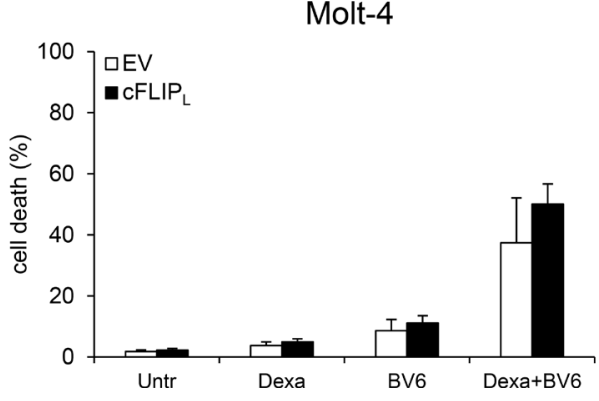


G

Reh
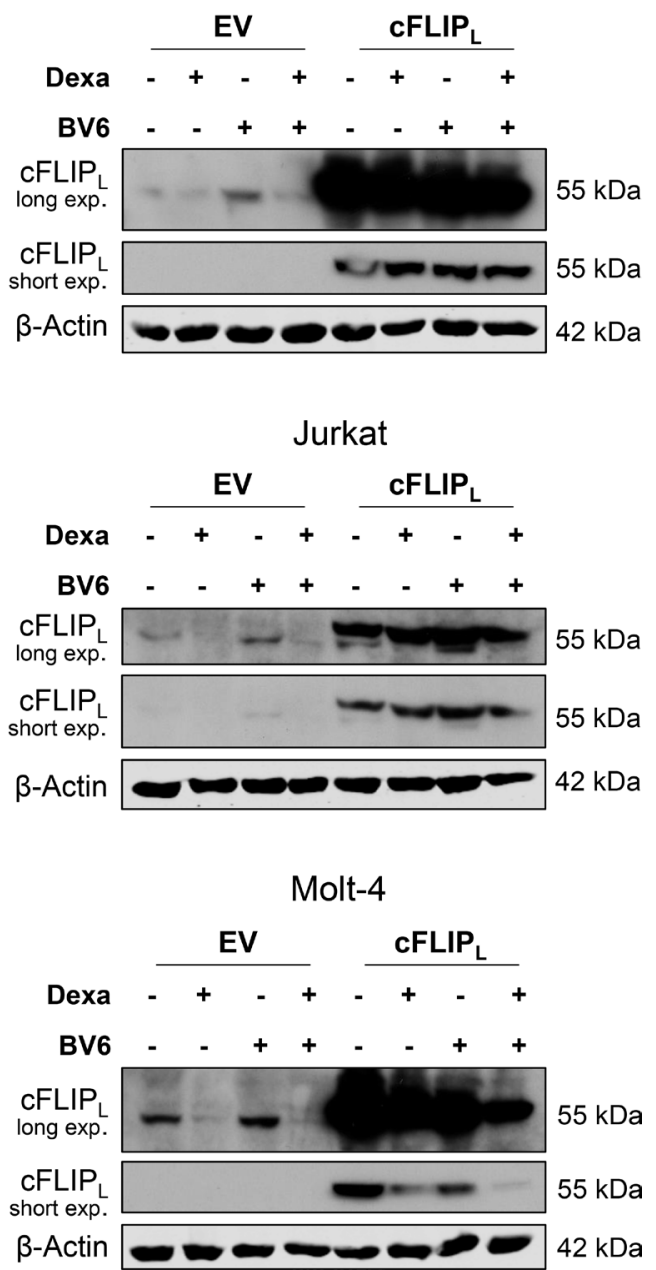

$\mathrm{H}$

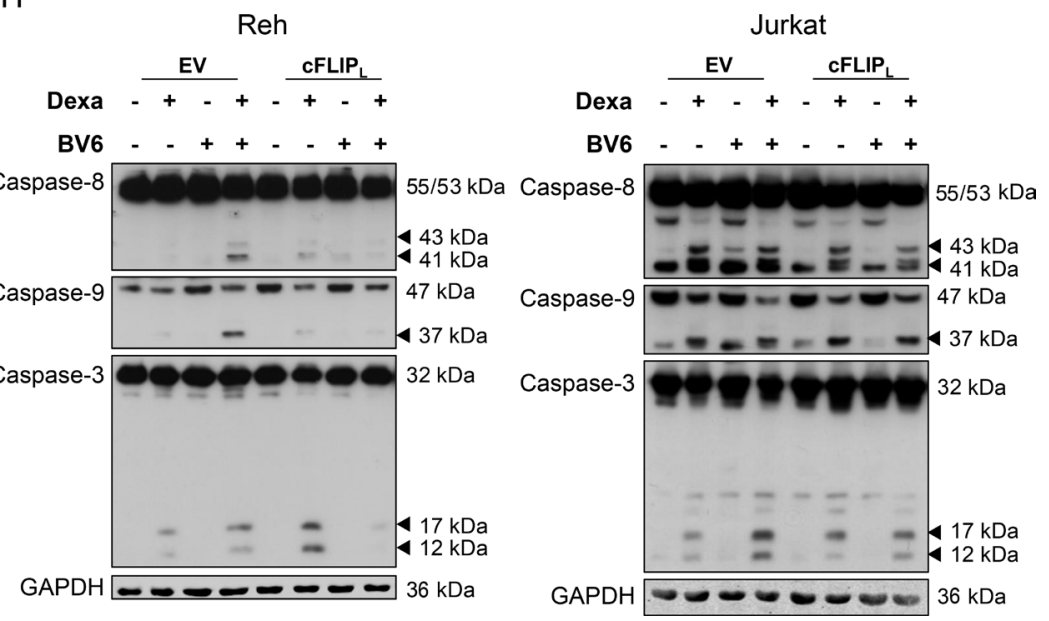

Figure 4: High cFLIP ${ }_{\mathrm{L}}$ levels impair Dexa/BV6-mediated cell death. $(\mathrm{A}, \mathrm{C}, \mathrm{E})$ Protein levels of $\mathrm{cFLIP}_{\mathrm{L}}$ were assessed by Western blotting in EV or cFLIP ${ }_{\mathrm{L}}$ overexpressing $\left(\mathrm{cFLIP}_{\mathrm{L}}\right)$ cells. GAPDH served as loading control. $(\mathbf{B}, \mathbf{D}, \mathbf{F}) \mathrm{cFLIP}_{\mathrm{L}}$ overexpressing $(\mathrm{OE})$ cells were treated with Dexa and/or BV6 (Jurkat: $300 \mu$ M Dexa; $7 \mu$ M BV6; Molt-4: $300 \mu$ M Dexa, $5 \mu$ M BV6; Reh: $300 \mu$ M Dexa, 0.3 $\mu \mathrm{M}$ BV6) for 24 hours (Reh, Molt-4) or 15 hours (Jurkat), respectively, and cell death was determined by FSC/SSC analysis and flow cytometry. Mean and SD of at least three independent experiments performed in triplicate are shown; ${ }^{* *} p<0.01,{ }^{* * *} p<0.001$. (G) OE cells were treated with $300 \mu \mathrm{M}$ Dexa and/or BV6 (Jurkat: $7 \mu \mathrm{M}$ BV6; Molt-4: $5 \mu \mathrm{M} \mathrm{BV6;} \mathrm{Reh:} 0.3 \mu \mathrm{M}$ BV6) for four hours. cFLIP expression was assessed by Western blotting. $\beta$-Actin served as loading control. (H) Reh and Jurkat OE cells were treated with $300 \mu \mathrm{M}$ Dexa and/ or BV6 (Jurkat: $7 \mu \mathrm{M}$ BV6; Reh: $0.3 \mu \mathrm{M}$ BV6) for six hours. Pro-caspase expression and caspase cleavage were analyzed by Western blotting. GAPDH served as loading control. 
by Dexa, since the pan-caspase inhibitor zVAD.fmk did not prevent Dexa-mediated loss of $\mathrm{CFLIP}_{\mathrm{L}}$.

As transcriptional or post-translational regulation, e.g. by caspases or the proteasome, are not primarily responsible for downregulation of $\mathrm{CFLIP}_{\mathrm{L}}$, it might be that translational processes are affected by Dexa. While in ALL cells glucocorticoids have been shown to repress genes involved in RNA, protein and nucleotide synthesis [39], which is in line with studies on other tumor entities [40] or tissues [41, 42], Dexa has recently been reported to not alter mRNA translation in ALL cell lines [43]. While the rapid kinetic of Dexa-mediated loss of $\mathrm{cFLIP}_{\mathrm{L}}$ protein similar to inhibition of protein synthesis by $\mathrm{CHX}$ is consistent with a block of translation or ribosomal proteins upon Dexa treatment, further studies are required to fully understand the mechanisms underlying Dexa-stimulated decrease of cFLIP $_{L}$.

By showing that Dexa-mediated downregulation of $\mathrm{cFLIP}_{\mathrm{L}}$ contributes to its sensitization to BV6-induced cell death, our study provides new insights into the molecular mechanisms of the cooperative induction of cell death by Dexa/BV6. As glucocorticoids are part of treatment regimens for ALL patients, our findings showing that Dexa and BV6 cooperate to induce cell death provide new concepts to enhance glucocorticoid sensitivity.
A

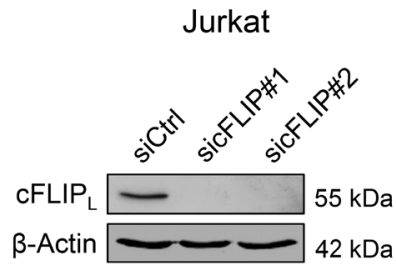

B

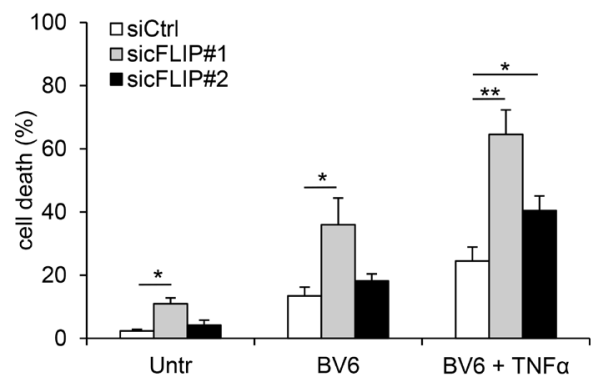

E

Molt-4

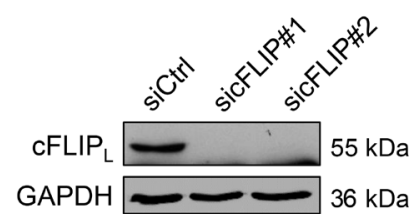

$\mathrm{F}$

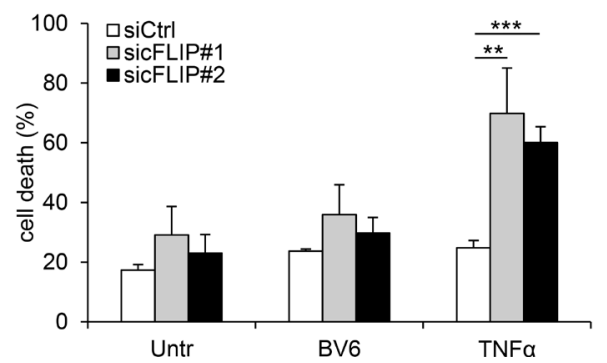

C

KOPN-8;11

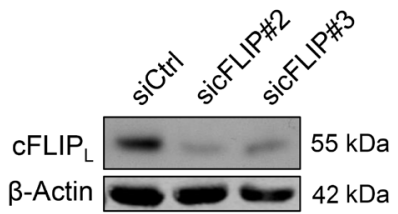

$\mathrm{D}$

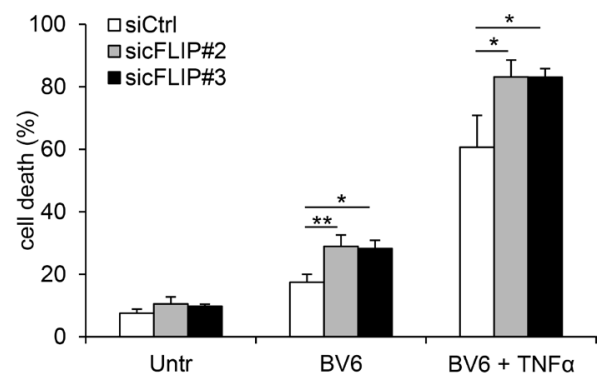

G

Reh

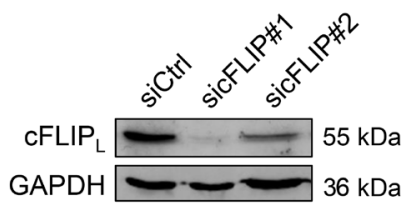

$\mathrm{H}$

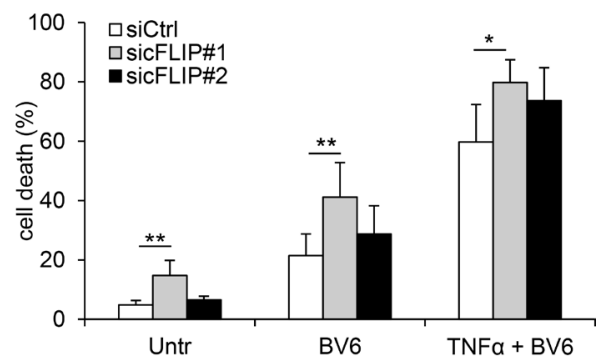

Figure 5: Knockdown of cFLIP increases BV6-mediated cell death. Cells were transiently transfected with two distinct siRNAs targeting cFLIP or control siRNA. (A, C, E, G) Protein expression of $\mathrm{cFLIP}_{\mathrm{L}}$ was analyzed by Western blotting. $\beta$-Actin or GAPDH served as loading control. (B, D, F, H) Cells were treated with BV6 and/or TNF $\alpha$ (Jurkat: $7 \mu \mathrm{M}$ BV6, $1 \mathrm{ng} / \mathrm{ml} \mathrm{TNF} \alpha$; KOPN-8;11 $\mu \mathrm{M}$ BV6, $1 \mathrm{ng} / \mathrm{ml} \mathrm{TNF} \alpha$; Molt-4: $5 \mu \mathrm{M}$ BV6, $100 \mathrm{ng} / \mathrm{ml} \mathrm{TNF} \alpha$; Reh: $0.1 \mu \mathrm{M} \mathrm{BV6,} 0.05 \mathrm{ng} / \mathrm{ml}$ TNF $\alpha$ ) for 24 hours or 15 hours (Jurkat), respectively. Cell death was determined by FSC/SSC analysis and flow cytometry. Mean and SD of at least three independent experiments performed in triplicate are shown; ${ }^{*} p<0.05,{ }^{* *} p<0.01,{ }^{* * *} p<0.001$. 


\section{MATERIALS AND METHODS}

\section{Cell culture and chemicals}

ALL cell lines were obtained from DSMZ (Braunschweig, Germany). Cells were cultured in RPMI 1640 medium (Life Technologies/Thermo Fisher Scientific, Darmstadt, Germany). Media were supplemented with $10 \%$ FCS (fetal calf serum) (Life Technologies/Thermo Fisher Scientific), $1 \mathrm{mM}$ pyruvate (Life Technologies/Thermo Fisher Scientific), $25 \mathrm{mM}$ HEPES (Life Technologies/ Thermo Fisher Scientific) and 1\% penicillin/streptomycin (Life Technologies/Thermo Fisher Scientific). The Smac mimetic BV6 was kindly provided by Genentech, Inc. (South San Francisco, CA, USA). The glucocorticoid Dexa was purchased from Sigma-Aldrich (Steinheim, Germany), the caspase inhibitor zVAD.fmk from Bachem (Heidelberg, Germany), the proteasome inhibitor Bortezomib from Selleckchem (Houston, TX, USA) and cycloheximide (CHX), E64d, CA-074 methyl ester, chloroquine, pepstatin A and Bafilomycin A from Sigma-Aldrich. All other chemicals were purchased from Sigma-Aldrich (Steinheim, Germany) or Carl Roth (Karlsruhe, Germany) unless indicated otherwise.

\section{Determination of cell death and proteasome activity}

Cell death was assessed by forward/side scatter (FSC/SSC) analysis and flow cytometry (FACS Canto II; BD Biosciences). 20S Proteasome activity was analyzed using CHEMICON 20S Proteasome Activity Assay Kit according to the manufacturer's instructions (Merck, Darmstadt, Germany).

\section{Western blot analysis}

Western blot analysis was performed as described previously [44] using the following antibodies: Mouse anti-cFLIP (Enzo Life Sciences, Lörrach, Germany), goat anti-cIAP1 (R\&D Systems, Wiesbaden, Germany), rat anti-cIAP2 (Enzo Life Sciences), mouse anti-XIAP (BD Biosciences, Heidelberg, Germany), rabbit anti-NIK (Cell Signaling Technologies, Beverly, MA USA), mouse anti-p100/p52 (Merck Millipore, Darmstadt, Germany), rabbit anti-p62 (MBL International, Woburn, MA, USA), mouse anti-Noxa (Enzo Life Sciences), rabbit antiMcl-1 (Enzo Life Sciences), mouse anti-caspase-8 (Enzo Life Sciences), rabbit anti-caspase-3 (Cell Signaling Technologies), rabbit anti-caspase-9 (Cell Signaling Technologies), mouse anti- $\beta$-actin (Sigma-Aldrich), mouse anti-GAPDH (HyTest, Turku, Finland), mouse anti-tubulin (Calbiochem, Merck Millipore, Darmstadt, Germany). Secondary antibodies conjugated to horseradish peroxidase (Santa Cruz Biotechnology, Santa Cruz, CA, USA) were used for enhanced chemiluminescence detection
(Amersham Bioscience, Freiburg, Germany). Alternatively, secondary antibodies labeled with IRDye infrared dyes were used for fluorescence detection (Odyssey Imaging System, LI-COR Bioscience, Bad Homburg, Germany). All Western blots shown are representative of two or three independent experiments.

\section{qRT-PCR analysis}

Total RNA was isolated using peqGOLD Total RNA Kit (peqlab/VWR, Darmstadt, Germany), cDNA synthesis was performed with $1 \mu \mathrm{g}$ RNA using RevertAid H Minus First Strand cDNA Synthesis Kit (Molecular Biology/ Thermo Fisher Scientific). To quantify gene expression qRT-PCR analysis was performed using SYBR Green Reaction Mix (Applied Biosystems, Darmstadt, Germany) with 7900HT Fast Real-Time PCR System (Applied Biosystems). The following primers were used: $28 \mathrm{~S}$ (forward: 5'-TTGAAAATCCGGGGGAGAG-3'; reverse: 5'-ACATTGTTCCAACATGCCAG-3'), 18S (forward: 5'-C GCAAATTACCCACTCCCG-3'; reverse: 5'-TTCCAAT TACAGGGCCTCGAA-3'), glucose 6-phosphate dehydrogenase (G6PDH) (forward: 5'-ATCGACCAC TACCTGGGCAA-3'; reverse: 5'-AGGCCCTGCACTACG TCTT-3'), RNA polymerase II (forward: 5'-GCACCACG TCCAATGACAT-3'; reverse: 5'-AATACCTTCGTCGG CGTG-3'), cFLIP (forward: 5'-GCTCACCATCCCTGTA CCTG-3'; reverse: 5'-CAGGAGTGGGCGTTTTCTT-3'), NIK (forward: 5'- CCAGCTGCCATCTCTATCATC-3'; reverse: 5'-AAAAAGTGGGGCTGAACTCT-3'). mRNA expression levels of genes of interest were normalized to three housekeeping genes and relative expression of target gene transcript and reference gene transcripts was calculated as $\Delta \Delta \mathrm{Ct}$.

\section{Gene silencing and transduction}

Knockdown experiments with small interfering RNA (siRNA) were performed using Neon Transfection System (Invitrogen, Karlsruhe, Germany) according to the manufacturer's instructions [45], using $80 \mathrm{nM}$ Silencer ${ }^{\mathbb{B}}$ Select siRNAs (Thermo Fisher Scientific) against cFLIP (\#1: s16864, \#2: s16865, \#3: s229912), or non-targeting control siRNA (no. 4390843). Jurkat, KOPN-8;11 and Molt-4 cells were treated 48 hours after transfection. Reh cells were transfected twice at intervals of 48 hours and treated 24 hours after the second transfection. Overexpression of cFLIP was performed by retroviral transduction using $\mathrm{cFLIP}_{\mathrm{L}}$ and the $\mathrm{pBABE}$-puro retroviral vector system. For virus production, Phoenix cells were transfected with $20 \mu \mathrm{g}$ DNA using calcium phosphate method. Virus-containing supernatant of Phoenix cells was filtered and added via spin transduction in the presence of $4 \mu \mathrm{g} / \mathrm{ml}$ protamine sulfate (SigmaAldrich) to Jurkat, Molt-4 or Reh cells. Transduced cells were selected with $5 \mu \mathrm{g} / \mathrm{ml}$ puromycin (Sigma-Aldrich). 


\section{Statistical analysis}

Statistical significance was assessed using Student's $t$-Test (two-tailed distribution, equal variance) calculated with Microsoft Excel (Munich, Germany).

\section{ACKNOWLEDGMENTS} assistance.

We thank C. Hugenberg for expert secretarial

\section{CONFLICTS OF INTEREST}

None to declare.

\section{FUNDING}

This work has been partially supported by grants from the BMBF (to S.F.).

\section{REFERENCES}

1. Lockshin RA, Zakeri Z. Cell death in health and disease. J Cell Mol Med. 2007; 11:1214-1224.

2. LaCasse EC, Baird S, Korneluk RG, MacKenzie AE. The inhibitors of apoptosis (IAPs) and their emerging role in cancer. Oncogene. 1998; 17:3247-3259.

3. Irmler M, Thome M, Hahne M, Schneider P, Hofmann K, Steiner V, Bodmer JL, Schroter M, Burns K, Mattmann C, Rimoldi D, French LE, Tschopp J. Inhibition of death receptor signals by cellular FLIP. Nature. 1997; 388:190-195.

4. Valnet-Rabier MB, Challier B, Thiebault S, Angonin R, Margueritte G, Mougin C, Kantelip B, Deconinck E, Cahn JY, Fest T. c-Flip protein expression in Burkitt's lymphomas is associated with a poor clinical outcome. Br J Haematol. 2005; 128:767-773.

5. Harris J, Ibrahim H, Amen F, Karadimitris A, Naresh KN, Macdonald DH. Cellular (FLICE) like inhibitory protein (cFLIP) expression in diffuse large B-cell lymphoma identifies a poor prognostic subset, but fails to predict the molecular subtype. Hematol Oncol. 2012; 30:8-12.

6. McLornan D, Hay J, McLaughlin K, Holohan C, Burnett AK, Hills RK, Johnston PG, Mills KI, McMullin MF, Longley DB, Gilkes A. Prognostic and therapeutic relevance of c-FLIP in acute myeloid leukaemia. Br J Haematol. 2013; 160:188-198.

7. Du X, Bao G, He X, Zhao H, Yu F, Qiao Q, Lu J, Ma Q. Expression and biological significance of c-FLIP in human hepatocellular carcinomas. J Exp Clin Cancer Res. 2009; 28:24.

8. Boatright KM, Deis C, Denault JB, Sutherlin DP, Salvesen GS Activation of caspases- 8 and -10 by FLIP(L). Biochem J. 2004; 382:651-657.

9. Scaffidi C, Schmitz I, Krammer PH, Peter ME. The role of c-FLIP in modulation of CD95-induced apoptosis. J Biol Chem. 1999; 274:1541-1548.
10. Feoktistova M, Geserick P, Kellert B, Dimitrova DP, Langlais C, Hupe M, Cain K, MacFarlane M, Hacker G, Leverkus M. cIAPs block Ripoptosome formation, a RIP1/ caspase-8 containing intracellular cell death complex differentially regulated by cFLIP isoforms. Mol Cell. 2011; 43:449-463.

11. Tenev T, Bianchi K, Darding M, Broemer M, Langlais C, Wallberg F, Zachariou A, Lopez J, MacFarlane M, Cain K, Meier P. The Ripoptosome, a signaling platform that assembles in response to genotoxic stress and loss of IAPs. Mol Cell. 2011; 43:432-448.

12. Fulda S, Vucic D. Targeting IAP proteins for therapeutic intervention in cancer. Nat Rev Drug Discov. 2012; 11:109-124.

13. Fulda S. Promises and challenges of Smac mimetics as cancer therapeutics. Clin Cancer Res. 2015; 21:5030-5036.

14. Tallen G, Ratei R, Mann G, Kaspers G, Niggli F, Karachunsky A, Ebell W, Escherich G, Schrappe M, Klingebiel T, Fengler R, Henze G, von Stackelberg A. Long-term outcome in children with relapsed acute lymphoblastic leukemia after time-point and site-ofrelapse stratification and intensified short-course multidrug chemotherapy: results of trial ALL-REZ BFM 90. J Clin Oncol. 2010; 28:2339-2347.

15. Belz K, Schoeneberger H, Wehner S, Weigert A, Bonig H, Klingebiel T, Fichtner I, Fulda S. Smac mimetic and glucocorticoids synergize to induce apoptosis in childhood ALL by promoting ripoptosome assembly. Blood. 2014; 124:240-250.

16. Varfolomeev E, Blankenship JW, Wayson SM, Fedorova AV, Kayagaki N, Garg P, Zobel K, Dynek JN, Elliott LO, Wallweber HJ, Flygare JA, Fairbrother WJ, Deshayes K, et al. IAP antagonists induce autoubiquitination of c-IAPs, NF-kappaB activation, and TNFalpha-dependent apoptosis. Cell. 2007; 131:669-681.

17. Vince JE, Wong WW, Khan N, Feltham R, Chau D, Ahmed AU, Benetatos CA, Chunduru SK, Condon SM, McKinlay M, Brink R, Leverkus M, Tergaonkar V, et al. IAP antagonists target cIAP1 to induce TNFalphadependent apoptosis. Cell. 2007; 131:682-693.

18. Noh HJ, Lee SJ, Sung EG, Song IH, Kim JY, Woo CH, Kwon TK, Lee TJ. CHOP down-regulates cFLIP(L) expression by promoting ubiquitin/proteasome-mediated cFLIP(L) degradation. J Cell Biochem. 2012; 113:3692-3700.

19. Geserick P, Hupe M, Moulin M, Wong WW, Feoktistova M, Kellert B, Gollnick H, Silke J, Leverkus M. Cellular IAPs inhibit a cryptic CD95-induced cell death by limiting RIP1 kinase recruitment. J Cell Biol. 2009; 187:1037-1054.

20. Zhao L, Yang G, Bai H, Zhang M, Mou D. NCTD promotes Birinapant-mediated anticancer activity in breast cancer cells by downregulation of c-FLIP. Oncotarget. 2017; 8:26886-26895. https://doi.org/10.18632/oncotarget.15848.

21. Crawford N, Stasik I, Holohan C, Majkut J, McGrath M, Johnston PG, Chessari G, Ward GA, Waugh DJ, 
Fennell DA, Longley DB. SAHA overcomes FLIPmediated inhibition of SMAC mimetic-induced apoptosis in mesothelioma. Cell Death Dis. 2013; 4:e733.

22. Cheung HH, Mahoney DJ, Lacasse EC, Korneluk RG. Down-regulation of c-FLIP Enhances death of cancer cells by smac mimetic compound. Cancer Res. 2009; 69:7729-7738.

23. Palacios C, Yerbes R, Lopez-Rivas A. Flavopiridol induces cellular FLICE-inhibitory protein degradation by the proteasome and promotes TRAIL-induced early signaling and apoptosis in breast tumor cells. Cancer Res. 2006; 66:8858-8869.

24. Grund K, Ahmadi R, Jung F, Funke V, Gdynia G, Benner A, Sykora J, Walczak H, Joos S, Felsberg J, Reife nberger G, Wiestler OD, Herold-Mende C, Roth W. Troglitazonemediated sensitization to TRAIL-induced apoptosis is regulated by proteasome-dependent degradation of FLIP and ERK1/2-dependent phosphorylation of BAD. Cancer Biol Ther. 2008; 7:1982-90.

25. Kim Y, Suh N, Sporn M, Reed JC. An inducible pathway for degradation of FLIP protein sensitizes tumor cells to TRAILinduced apoptosis. J Biol Chem. 2002; 277:22320-22329.

26. Haag C, Stadel D, Zhou S, Bachem MG, Moller P, Debatin KM, Fulda S. Identification of c-FLIP(L) and c-FLIP(S) as critical regulators of death receptor-induced apoptosis in pancreatic cancer cells. Gut. 2011; 60:225-237.

27. Kreuz S, Siegmund D, Scheurich P, Wajant H. NF-kappaB inducers upregulate cFLIP, a cycloheximide-sensitive inhibitor of death receptor signaling. Mol Cell Biol. 2001; 21:3964-3973.

28. Micheau O, Lens S, Gaide O, Alevizopoulos K, Tschopp J. NF-kappaB signals induce the expression of c-FLIP. Mol Cell Biol. 2001; 21:5299-5305.

29. Heck S, Bender K, Kullmann M, Göttlicher M, Herrlich P, Cato AC. I kappaB alpha-independent downregulation of NF-kappaB activity by glucocorticoid receptor. EMBO J. 1997; 16:4698-707.

30. Machuca C, Mendoza-Milla C, Cordova E, Mejia S, Covarrubias L, Ventura J, Zentella A. Dexamethasone protection from TNF-alpha-induced cell death in MCF-7 cells requires NF-kappaB and is independent from AKT. BMC Cell Biol. 2006; 7:9.

31. Beck IM, Vanden Berghe W, Vermeulen L, Bougarne N, Vander Cruyssen B, Haegeman G, De Bosscher K. Altered subcellular distribution of MSK1 induced by glucocorticoids contributes to NF-kappaB inhibition. EMBO J. 2008; 27:1682-93.

32. Toivonen HT, Meinander A, Asaoka T, Westerlund M, Pettersson F, Mikhailov A, Eriksson JE, Saxen H. Modeling reveals that dynamic regulation of c-FLIP levels determines cell-to-cell distribution of CD95-mediated apoptosis. J Biol Chem. 2011; 286:18375-18382.

33. Chang L, Kamata H, Solinas G, Luo JL, Maeda S, Venuprasad K, Liu YC, Karin M. The E3 ubiquitin ligase itch couples JNK activation to TNFalpha-induced cell death by inducing c-FLIP(L) turnover. Cell. 2006; 124:601-613.
34. Zhang G, Liu J, Zhang Y, Qu J, Xu L, Zheng H, Liu Y, Qu X. Cbl-b-dependent degradation of FLIP(L) is involved in ATO-induced autophagy in leukemic K562 and gastric cancer cells. FEBS Lett. 2012; 586:3104-3110.

35. Fukazawa T, Fujiwara T, Uno F, Teraishi F, Kadowaki Y, Itoshima T, Takata Y, Kagawa S, Roth JA, Tschopp J, Tanaka N. Accelerated degradation of cellular FLIP protein through the ubiquitin-proteasome pathway in p53-mediated apoptosis of human cancer cells. Oncogene. 2001; 20:5225-5231.

36. Liu X, Yue P, Schonthal AH, Khuri FR, Sun SY. Cellular FLICE-inhibitory protein down-regulation contributes to celecoxib-induced apoptosis in human lung cancer cells. Cancer Res. 2006; 66:11115-11119.

37. Seo SU, Cho HK, Min KJ, Woo SM, Kim S, Park JW, Kim SH, Choi YH, Keum YS, Hyun JW, Park HH, Lee SH, Kim DE, Kwon TK. Thioridazine enhances sensitivity to carboplatin in human head and neck cancer cells through downregulation of c-FLIP and Mcl-1 expression. Cell Death Dis. 2017; 8:e2599.

38. Scudiero I, Zotti T, Ferravante A, Vessichelli M, Reale C, Masone MC, Leonardi A, Vito P, Stilo R. Tumor necrosis factor (TNF) receptor-associated factor 7 is required for TNFalpha-induced Jun NH2-terminal kinase activation and promotes cell death by regulating polyubiquitination and lysosomal degradation of c-FLIP protein. J Biol Chem. 2012; 287:6053-6061.

39. Obexer P, Certa U, Kofler R, Helmberg A. Expression profiling of glucocorticoid-treated T-ALL cell lines: rapid repression of multiple genes involved in RNA-, protein- and nucleotide synthesis. Oncogene. 2001; 20:4324-4336.

40. Meyuhas O, Thompson EA Jr, Perry RP. Glucocorticoids selectively inhibit translation of ribosomal protein mRNAs in P1798 lymphosarcoma cells. Mol Cell Biol. 1987; 7:2691-99.

41. Fussell JC, Kelly FJ. Effects of dexamethasone on lung protein turnover. Biochem J. 1991; 273:93-97.

42. Burrin DG, Wester TJ, Davis TA, Fiorotto ML, Chang X. Dexamethasone inhibits small intestinal growth via increased protein catabolism in neonatal pigs. Am J Physiol. 1999; 276:E269-277.

43. Aneichyk T, Bindreither D, Mantinger C, Grazio D, Goetsch K, Kofler R, Rainer J. Translational profiling in childhood acute lymphoblastic leukemia: no evidence for glucocorticoid regulation of mRNA translation. BMC Genomics. 2013; 14:844.

44. Fulda S, Strauss G, Meyer E, Debatin KM. Functional CD95 ligand and CD95 death-inducing signaling complex in activation-induced cell death and doxorubicin-induced apoptosis in leukemic T cells. Blood. 2000; 95:301-308.

45. Schenk B, Fulda S. Reactive oxygen species regulate Smac mimetic/TNFalpha-induced necroptotic signaling and cell death. Oncogene. 2015; 34:5796-5806. 